\title{
Improvement the Dynamic Voltage Profile by a Voltage Stabilizer in Microgrids with a Type of Inverter Based Resource
}

\author{
Maedeh Mahzarnia \\ Dept. of Electrical Engineering, Noshirvani university of Babol, Babol, Iran \\ E-mail: maedehmahzarnia@yahoo.com \\ Abdolreza Sheikholeslami
Dept. of Electrical Engineering, Noshirvani university of Babol, Babol, Iran \\ E-mail:asheikh@nit.ac.ir
}

\begin{abstract}
The electrical distances between reactive power sources and the loads that need reactive compensation are not too much in microgrids. Thus, a coordinated compensation of reactive sources should be implemented to avoid a fast voltage collapse and improve the dynamic voltage profile by proposing a Micro Grid Voltage Stabilizer (MGVS). This stabilizer was used in microgrids with synchronous machine based resources. Main purpose of this research is verify the performance of the stabilizer by applying it to microgrids containing power-electronic converter based distributed generations (DGs). So that a 21-bus IEEE microgrid with three photovoltaic (PV) resources is tested. At first, PV resource and all of its needed equipments, are modeled. Then a control model of the stabilizer with appropriate parameters, is presented. Voltage deficiency of the system is the input of the stabilizer, and the output signal of the stabilizer, is divided between the DGs in order to provide required reactive power. The dynamic voltage profile of buses in presence of MGVS and its absence has been compared by imply ing disturbances. Simulation results in MATLAB/SIMULINK show that the dynamic voltage profile of buses improves satisfactorily with the addition of MGVS.
\end{abstract}

Index Terms - Microgrid, Voltage Stabilizer, Photovoltaic Resource, DC-Bus-Voltage-Controlled Inverter, Closed Loop DC-DC Boost Converter

\section{Introduction}

Considering restructuring the electricity market in recent years, power systems move toward the application of distributed generation (DG) recourses. Widespread application of DGs in power system caused challenges related to stability and reliability of power system. Therefore, a new structure is suggested for grid called microgrid, which is a controllable unit that works in parallel with main grid. Microgrid is composed of DGs, loads, and controllers and in black out and disturbance situation can change in to islanding mode through a Static switch, hence power accessibility is remained in an agreeable level and overall black out is prevented [1]. Regarding abovementioned descriptions, it can be said that microgrids prevent voltage instability due to sudden change of load in main grid, and improve stability and reliability of the power system. On the other hand, presence of weak microgrids can leads to extreme voltage drop or overvoltage and even voltages collapse of the system. Proper dynamic reactive capability is required for preventing fast voltage drop. In fact, a coordinated effort among the reactive sources increases the efficiency of these resources. In microgrids, electrical distances between reactive sources and loads that require reactive compensation are not too much. Also, some loads may be sensitive to voltage variations and all DGs have not the capability of reactive power compensation in dynamic mode. Therefore, a coordinated compensation between reactive sources should be performed to enhance dynamic voltage stability of the microgrid and improving voltage profile of the buses $[2,3,4]$.

Some researches are carried out for voltage stability in microgrids using different methods. for instance, a DSTATCOM is presented at [5] to enhance the stability of the system. During Power imbalance in the microgrid, the DSTATCOM holds the microgrid voltage for few cycles and allows the protection system to shed load and stabilize the system. A rapid detection of the load shedding requirement is very crucial for the success of this scheme. If the load is not shed within 23 cycles, the system voltage will collapse even in the presence of DSTATCOM. Another drawback of this strategy is increasing the cost of the system due to use of power electronics devices in stabilizer circuit instead of using control devices. Also [6] presented a stabilitytype algorithm and a stabilizer that applied to systems with low dynamic, where sources are synchronous 
machine based DGs. Presented research activities did not applied to microgrids containing inverter-based DGs.

Therefore, proposing a method is essential to overcome these problems. Hence, a microgrid voltage stabilizer (MGVS) has been designed by presenting a control model in this paper. Main objective of this research is to apply the MGVS in microgrids containing power electronic converter based DGs. So that, photovoltaic $(\mathrm{PV})$ resource, that has variable DC output, is selected in this paper.

The IEEE 21-bus microgrid is considered as a test case. The suggested dynamic model of microgrid and controller are simulated in MATLAB/Simu link. In this analysis, the applied dynamic disturbance to the grid is considered three-phase short-circuit fault and simulation results are compared in two modes (with and without MGVS).

In next section, model of utilized DG in the test case microgrid and all of its elements are discussed in detail. In section 3, the suggested MGVS, for such a microgrid is investigated. Simulation results and conclusion are presented in section 4 and 5, respectively.

\section{Modeling the Photovoltaic Resource and Its Important Elements}

As mentioned before, the under survey microgrid contains three power-electronic based DGs, which are photovoltaic $(\mathrm{PV})$ resources. In this section, model of photovoltaic system and its elements, including closedloop DC-DC boost converter, DC-bus-voltagecontrolled inverter, batteries and etc. are presented. It should be noted that main reason for the use of mentioned type of inverter is its appropriation for the microgrid voltage stabilizer that has been explained in section 2.1 in detail.

In general, the different parts of a PV system can be classified as follows [7]:

1. Solar cells section (solar modules or panels)

2. Consumer or electric load

3. Medium section or desired power section

Figure 1 shows equivalent circuit of a PV cell in which $\mathrm{I}$ is module current, $\mathrm{V}$ module voltage, $\mathrm{I}_{\mathrm{ph}}$ photo current, m number of series cell in a module, $\mathrm{R}_{\mathrm{s}}$ series resistance of cell and $R_{p}$ shunt resistance of polycrystalline cell. Many of these cells in a solar module are connected in series in order to achieve higher level of voltage. Photovoltaic source in this research consists of six cells which are connected to each other in series to form a module with an approximate voltage of 100 volts. The specifications of each cell and the derived module are given in appendix.

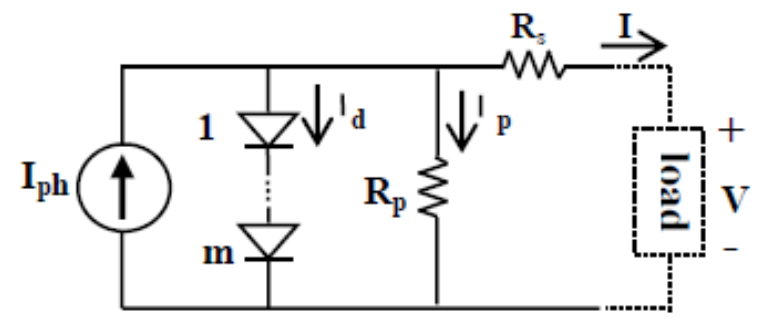

Fig. 1: Simple Equivalent Circuit of PV Cell

In medium section or desired power section, electric energy of PV systems is managed in proportion to the demand of consumer. These devices are usually formed by storage and support system (battery), charge control, inverter and etc.

\subsection{Closed-Loop DC-DC Boost Converter and Inverter Model Appropiate for MGVS}

Output power of the solar panels is in the DC form and should be converted to AC power via inverter in order to inject this power to the grid. Figure 2 shows schematic view of inverters connection to the PV systems. As shown in this figure, DC output of the solar cell should be increased using a step-up DC-DC converter and then regarding to the type of system performance, it is connected to AC grid through a typical inverter.

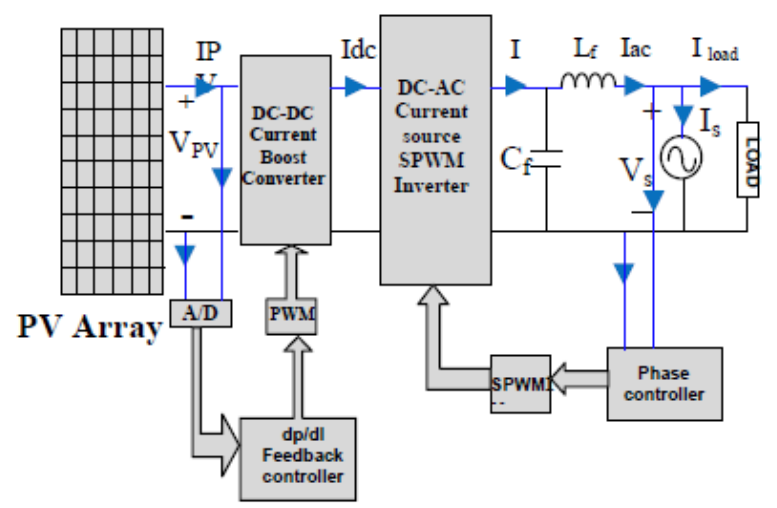

Fig. 2: Inverters Connection to the PV Systems

Generally, since output of DC-DC converter has ripple, this is sue affects the accuracy of the results. Hence, closed-loop DC-DC converter has to be used in order to deliver a s mooth DC output (or with minimu m ripple) to the inverter [8,9]. Figure 3 shows simulated sample of this converter in Matlab. And Figure 4 shows an inverter appropriate for MGVS which is an average model and "DC-bus-voltage-controlled" type of inverter [10].

When the microgrid is connected to the main grid, the inverter is controlled to inject a given active and reactive power. This mode is known as PQ mode of control. But the under-study microgrid, is considered in the islanded mode of operation, in which the inverter 
control mode deviates from PQ controller mode and switches to voltage and frequency control mode $[11,12]$.

Hence, the utilized inverter should primarily be capable to control active and reactive power. If so, regarding the "frequency - active power" and "voltage reactive power" droop curves, the frequency and voltage can be controlled too, in the islanded microgrid.

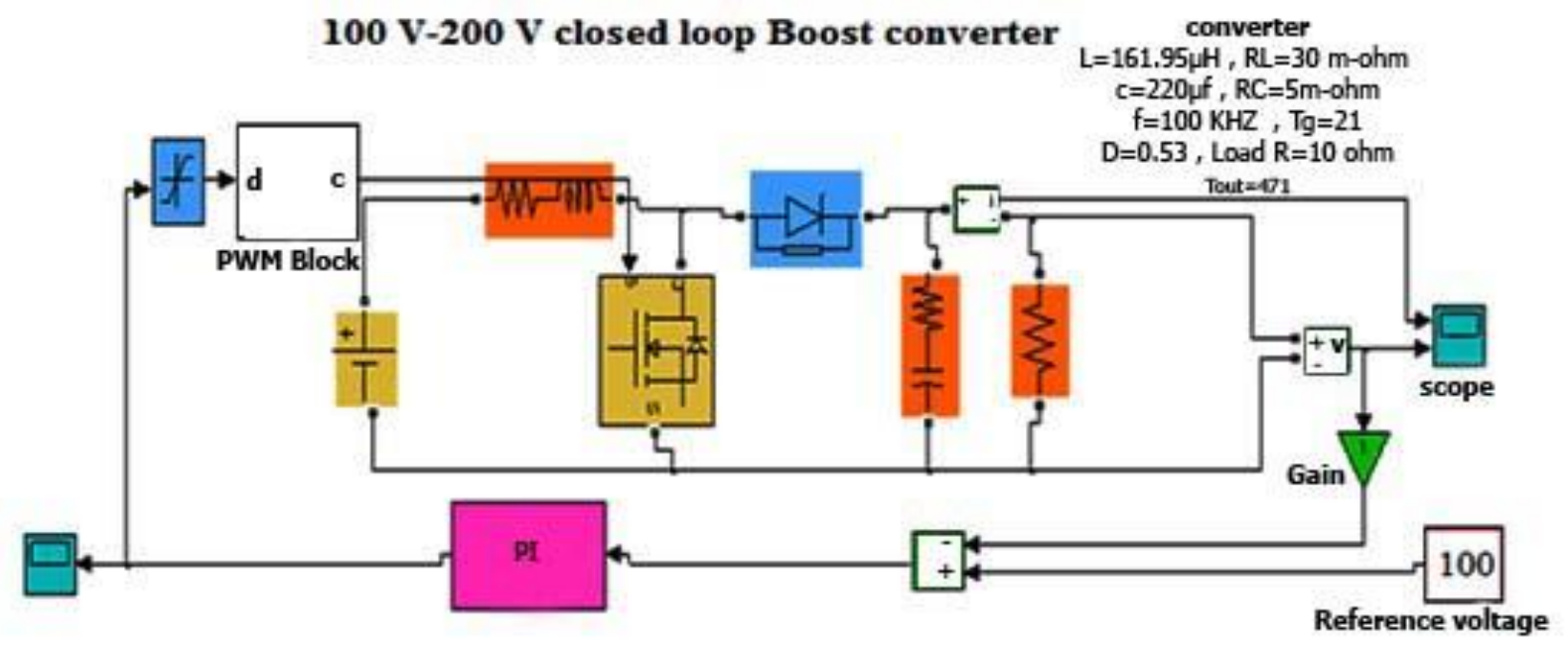

Fig. 3: Simulation of Closed-Loop DC-DC Boost Converter in MATLAB/Simulink

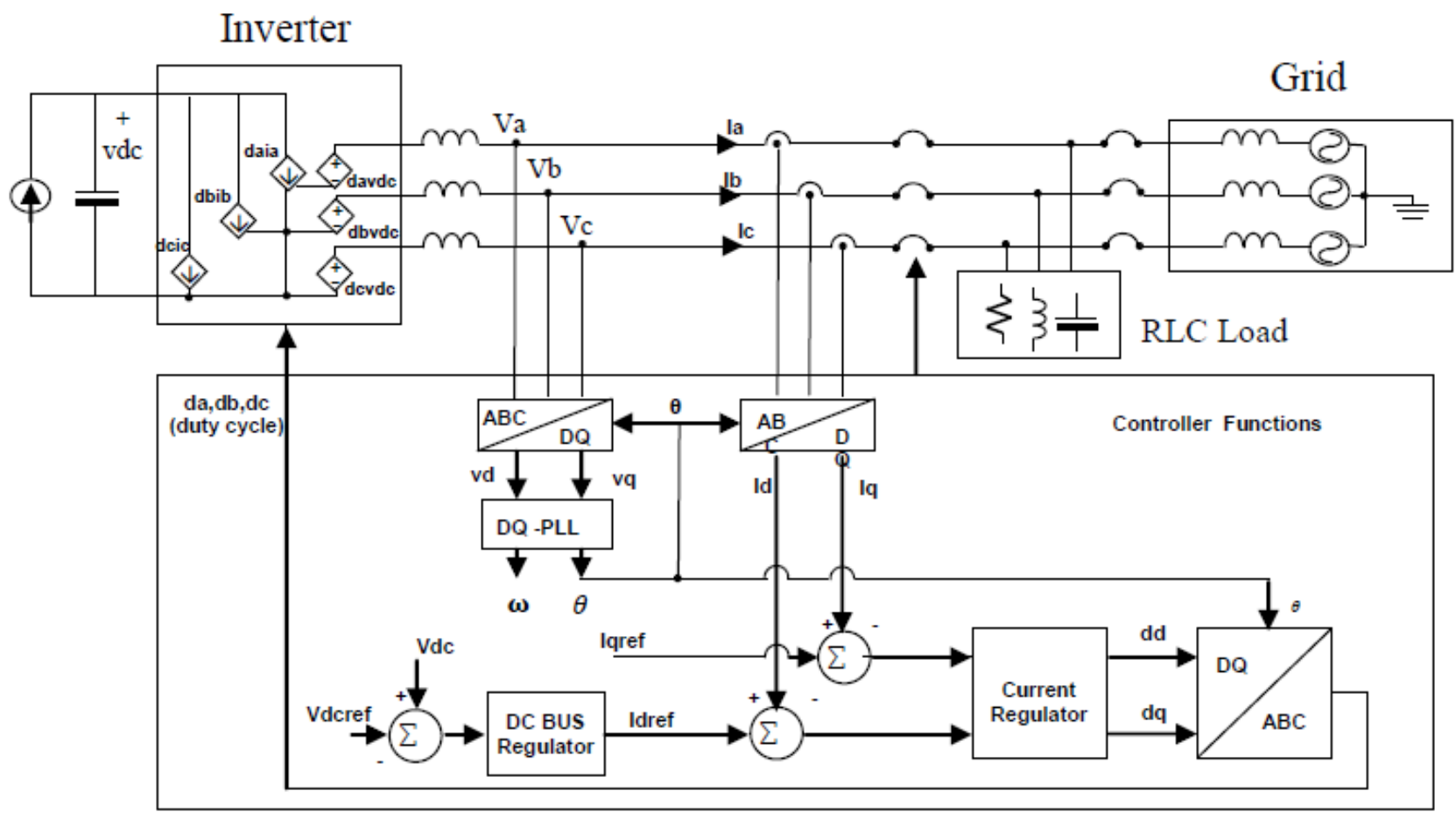

Fig. 4: DC-Bus-Voltage-Controlled Inverter Schematic

It should be mentioned that three phase symmetrical voltage and current are considered for operation of the proposed inverter. As a result, their zero components are zero. Therefore, if the reference frame of $\mathrm{dq}$ is selected in a manner which rotates synchronized to the microgrid voltages then we would have $\mathrm{V}_{\mathrm{q}}=0$.
Active and reactive powers equations are given in equations (1) and (2). By considering $\mathrm{V}_{\mathrm{q}}=0$, these formula could be shortened as equations (3) and (4).

$$
P=V_{d} I_{d}+V_{q} I_{q}
$$




$$
\begin{aligned}
& \mathrm{Q}=\mathrm{V}_{\mathrm{q}} \mathrm{I}_{\mathrm{d}}-\mathrm{V}_{\mathrm{d}} \mathrm{I}_{\mathrm{q}} \\
& \mathrm{P}=\mathrm{V}_{\mathrm{d}} \mathrm{I}_{\mathrm{d}} \\
& \mathrm{Q}=-\mathrm{V}_{\mathrm{d}} \mathrm{I}_{\mathrm{q}}
\end{aligned}
$$

Therefore, having reference values of active and reactive power and also regarding to equations (3) and (4) and voltage measurement of bus-bar, related to connecting the inverter to the microgrid, in each instant, the reference values of $d$ and $q$ axis currents could be derived as equations (5) and (6).

$$
\begin{gathered}
I_{d, \text { ref }}=\frac{P_{\text {ref }}}{V_{d}} \\
I_{q, \text { ref }}=-\frac{Q_{\text {ref }}}{V_{d}}
\end{gathered}
$$

As a result, generated active and reactive power could be controlled by controlling the inverter's $d$ and $q$ axis currents.

As it would be explained in detail in section 3, the output of the proposed voltage stabilizer is distributed between the DGs located in the microgrid. The part of stabilizer output related to each PV resource (or each power electronic converter based resources), should be applied on its inverter. Since the signal type of this controller output is voltage, the control section of the employed inverter should have the capability to deal with output voltage of PV, reference voltage and also output voltage of MGVS, as three input signals, in addition to active and reactive power control (by $\mathrm{I}_{\mathrm{d}}$ and $\mathrm{I}_{\mathrm{q}}$ control). Therefore, as it shown in figure 4 , the employed inverter is a "DC-bus-voltage-controlled" type inverter, which, in turn, is a kind of "average model" inverters. In this case, the share of PV resource from stabilizer output, should be added to the collector block, located in the control section of the inverter and prior to "DC bus regulator" block (that in fact a PI controller block), as the $3^{\text {rd }}$ input.

\subsection{Energy Storage Resource (Battery)}

The last section of PV systems is energy storage section, which is required due to limitation of solar energy. The storage process is performed through electrochemical batteries in PV power-plants. Batteries increase the service time and electricity supply in nights or in hours that solar light cannot provide required power for consumers [13]. These storage elements should compensate the effects of sudden changes of PV power-plants. Thus the capacity of storage system could be calculated by computing the maximu $m$ variations, on the bas is of system parameters.

Figure 5 shows how to connect a battery to the photovoltaic system.

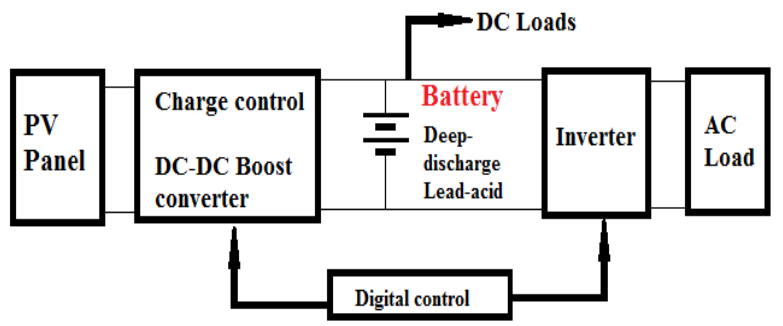

Fig. 5: Connection a Battery to Photovoltaic System

\section{Modeling of "Microgrid Voltage Stabilizer" and Applying It To Microgrid}

In every system, bus voltages are considered as important performance factors which should lie within a specific range. Different disturbances could result in voltage drop. On the other hand, in microgrids, electrical distances between resources and loads are not too much and reactive power could be transferred from resource to load, therefore, a stabilizer which acts on this basis, could be used in microgrids. "Microgrid Voltage Stabilizer" (MGVS), works similar to $\mathrm{PSS}^{1}$ in traditional power systems and its main purpose is to ensure that the voltage remains within the set point values by adjusting reactive power generated or consumed. For example, at the time of voltage drop, this controller provides more reactive power for microgrid and so prevents any voltage collapse [14,15].

At the input of this controller, the terminal voltages are compared with the reference voltage and the error voltage, that is the difference value between them, is filtered using a low pass filter and multiplied by a gain constant and so the "droop control" is obtained in this way. Moreover, with respect to the "reactive power voltage" droop curve, the injected reactive power required by distributed generation resources, to adjust terminal voltage at a set point value, could be estimated from output signal of this controller.

Corresponding differential equations that indicate the performance of MGVS are given in equations (7) and (8):

$$
\begin{aligned}
& \dot{x}(t)=-\frac{1}{T_{1}} x(t)+\frac{K\left(T_{1}-T_{2}\right)}{T_{1}^{2}} \Delta V_{e r r} \\
& V_{M G V S}(t)=x(t)+K \frac{T_{2}}{T_{1}} \Delta V_{\text {err }}
\end{aligned}
$$

Model of MGVS, that formed by a Lead-Lag block, is shown in Figure 6, but for easy implementation in Matlab/simulink, the equivalent block diagram of it, can be used (Figure 7).

1 . Power Sy stem Stabilizer 


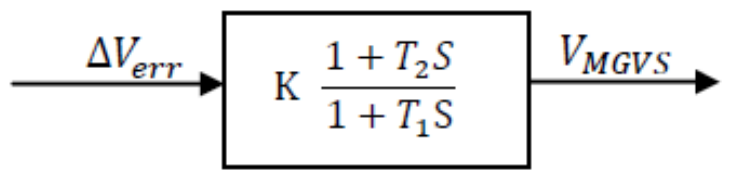

Fig. 6: Model of Microgrid Voltage Stabilizer (MGVS)

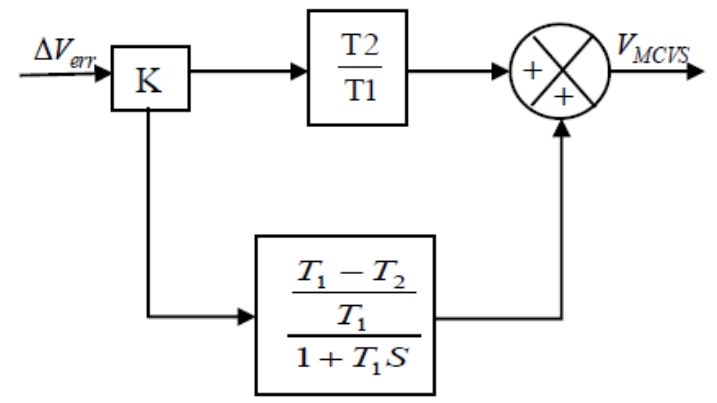

Fig. 7: Simplified Model of Microgrid Voltage Stabilizer (MGVS)

Input of MGVS is a fractional of system voltage in dynamic mode. Per unit difference $\left(\Delta V_{\text {ierr }}\right)$ between ideal voltage $\left(\mathrm{V}_{\text {ides }}\right)$ and dynamic voltage $\left(\mathrm{V}_{\text {idyn }}\right)$ is calculated for all load buses (equation (9)).

$$
\Delta \mathrm{V}_{\text {err } \mathrm{i}}=\frac{\mathrm{V}_{\text {des } \mathrm{i}}-\mathrm{V}_{\text {dyn } \mathrm{i}}}{\mathrm{V}_{\text {des } \mathrm{i}}}, \mathrm{i}=1,2, \ldots, \mathrm{l}
$$

Then, for determination of total fractional voltage, according to equation (10), weighted average $\left(\Delta \mathrm{V}_{\text {err }}\right)$ is carried out on fractional voltage of all load buses.

$$
\Delta \mathrm{V}_{\mathrm{err}}=\frac{\alpha_{1} \Delta \mathrm{V}_{\mathrm{err} 1}+\alpha_{2} \Delta \mathrm{V}_{\mathrm{err} 2}+\cdots \ldots \ldots \alpha_{\mathrm{i}} \Delta \mathrm{V}_{\mathrm{errl}}}{\alpha_{1}+\alpha_{2}+\cdots \ldots . . \alpha_{\mathrm{i}}}
$$

Weighting factor of each bus is defined based on importance of that bus (for example induction motor loads comparing to resistive loads are more sensitive to disturbances). For $\mathrm{i}=1$ to $\mathrm{i}=\mathrm{L}$ load buses, their termed as $\alpha_{1}, \alpha_{2}, \ldots, \alpha_{L}$; and their values for the test-case microgrid are given in Table 1.

Table 1: Weighting Factors for Load Buses

\begin{tabular}{|c|c|c|c|c|c|c|}
\hline$\alpha_{1}$ & $\alpha_{7}$ & $\alpha_{11}$ & $\alpha_{13}$ & $\alpha_{15}$ & $\alpha_{19}$ & $\alpha_{21}$ \\
\hline 0.1 & 0.094 & 0.119 & 0.096 & 0.302 & 0.216 & 0.073 \\
\hline
\end{tabular}

As shown in figure $7, \Delta \mathrm{V}_{\text {err }}$ is supplied by a lead-lag block with gain constant $\mathrm{K}$ and time constants $\mathrm{T} 1$ and T2. The values of $T_{1}, T_{2}$ and $K$ for the under-study microgrid, that resulted by the use of Eigen-Values method, are given in Table 2.

Table 2: MGVS Control Parameters

\begin{tabular}{|c|c|c|}
\hline $\mathbf{K}$ & $\mathbf{T}_{\mathbf{1}}$ & $\mathbf{T}_{\mathbf{2}}$ \\
\hline 10 & 1.5 & 0.2 \\
\hline
\end{tabular}

Output of MGVS i.e. $V_{M G V S}$ is divided between DGs based on generation reserve, nature of DGs and closeness of them to the voltage sensitive loads. Equation (11) shows how of this divis on on the basis of weighting factors. These factors for generator buses (1 to $\mathrm{g}$ ), are $\beta_{1}, \beta_{2}, \ldots, \beta_{\mathrm{g}}$ and their values are given in Table 3.

$$
\mathrm{V}_{\mathrm{MGVSi}}=\beta_{\mathrm{i}} \mathrm{V}_{\mathrm{MGVS}}, i=1,2, \ldots . . g
$$

Table 3: Weighting Factors for Generator Buses

\begin{tabular}{|c|c|c|}
\hline$\beta_{1}$ & $\beta_{2}$ & $\beta_{3}$ \\
\hline 0.3581 & 0.3663 & 0.2756 \\
\hline
\end{tabular}

In the tested microgrid, $V_{M G V S 1}, V_{M G V S 2}$ and $V_{M G V S 3}$ are shares of MGVS output which should be applied on three PV resources. As explained in section 2-1-1, they are added as the $3^{\text {rd }}$ input to the control part of the inverters of first, second and third PV resources, respectively.

\section{Simulation Results}

An IEEE 21-bus microgrid in islanded mode of operation is considered as test system of this paper (see Figure 14). Simulations are carried out in MATLAB/Simulink. A Three-phase short circuit fault that applied to bus 15 is considered as disturbance. The improvement rate of dynamic voltage profile by the use of MGVS, is investigated in this analysis.

During short-circuit fault, large currents flow from generator buses to faulted load bus which results in the drop of the voltage of other buses. At this time, MGVS helps the microgrid to use the reactive power reserve efficiently and improve the dynamic voltage stability.

The applied three-phase fault in this simulation, starts at $15^{\text {th }}$ cycle $(t=0.25)$ and continues to the end of cycle $70^{\text {th }}(t=1.167)$.

Simulation results related to load buses 11, 19, 21, and bus 15 that is the faulted load bus, are shown in Figures (8), (9), (10) and (11), respectively. By comparison of the dynamic voltages of load buses, in the systems with and without MGVS, it is shown that dynamic their voltage profile is improved satisfactorily by the use of MGVS.

In addition, Figures (12) and (13) are sample figures that exhibit a comparis on of reactive power generation related to microgrid resources, in the presence of stabilizer and its absence. 


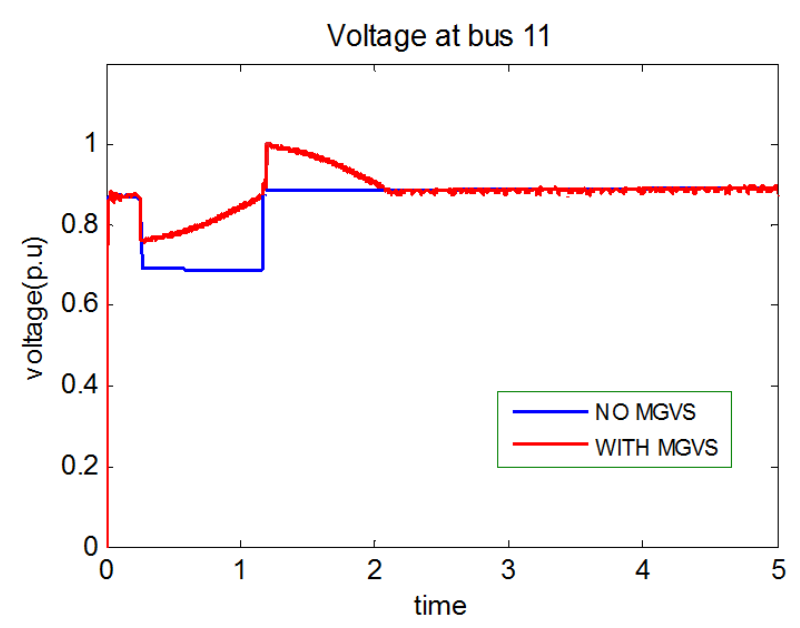

Fig. 8: Comparison of Voltage Profile Related to Bus 11, with MGVS and without It

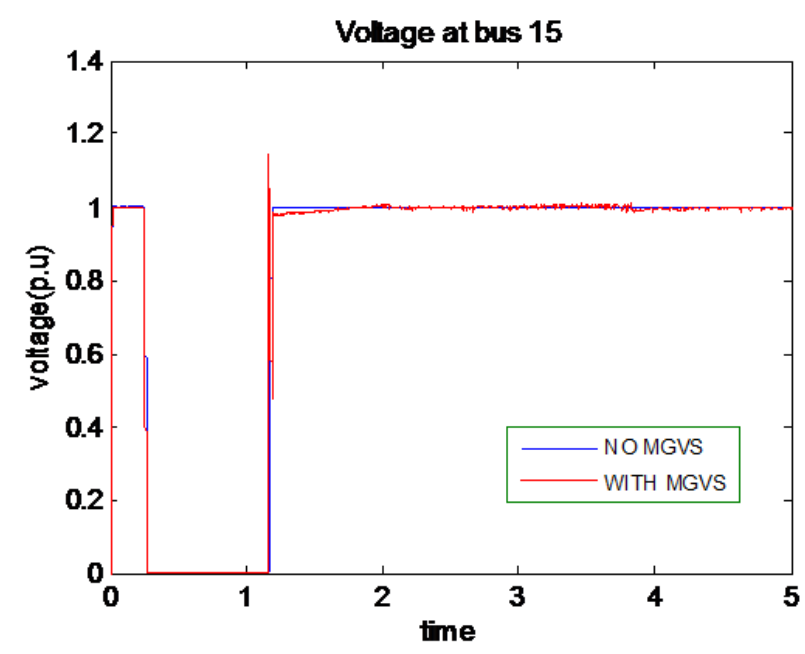

Fig. 9: Comparison of Voltage Profile Related to Bus 15 (Faulted Bus), with MGVS and without It

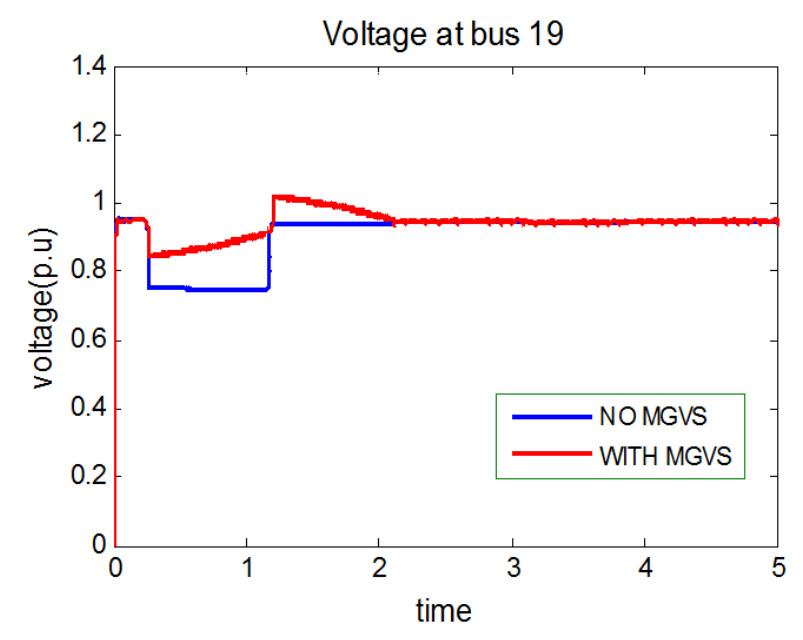

Fig. 10: Comparison of Voltage Profile Related to Bus 19, with MGVS and without It

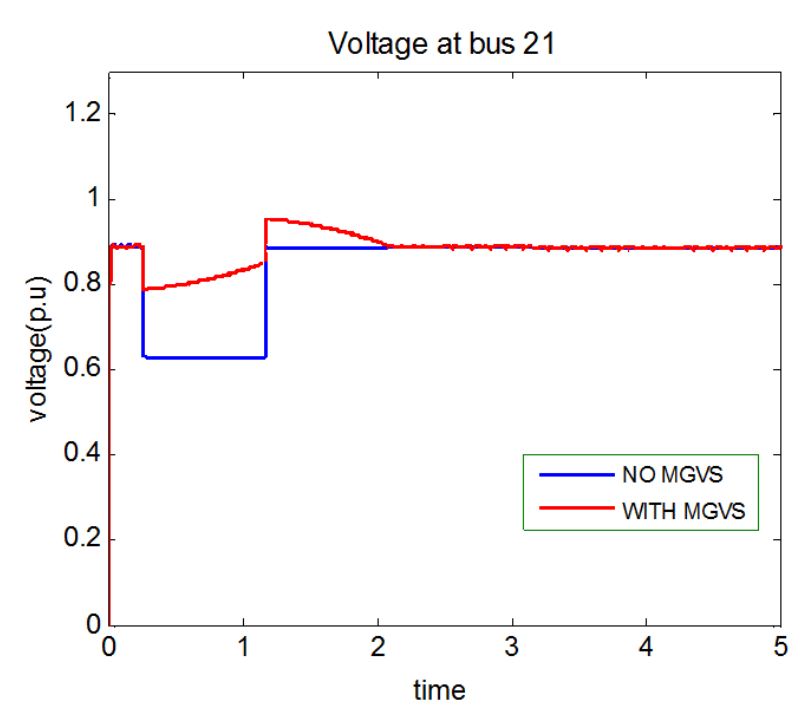

Fig. 11: Comparison of Voltage Profile Related to Bus 21, with MGVS and without It

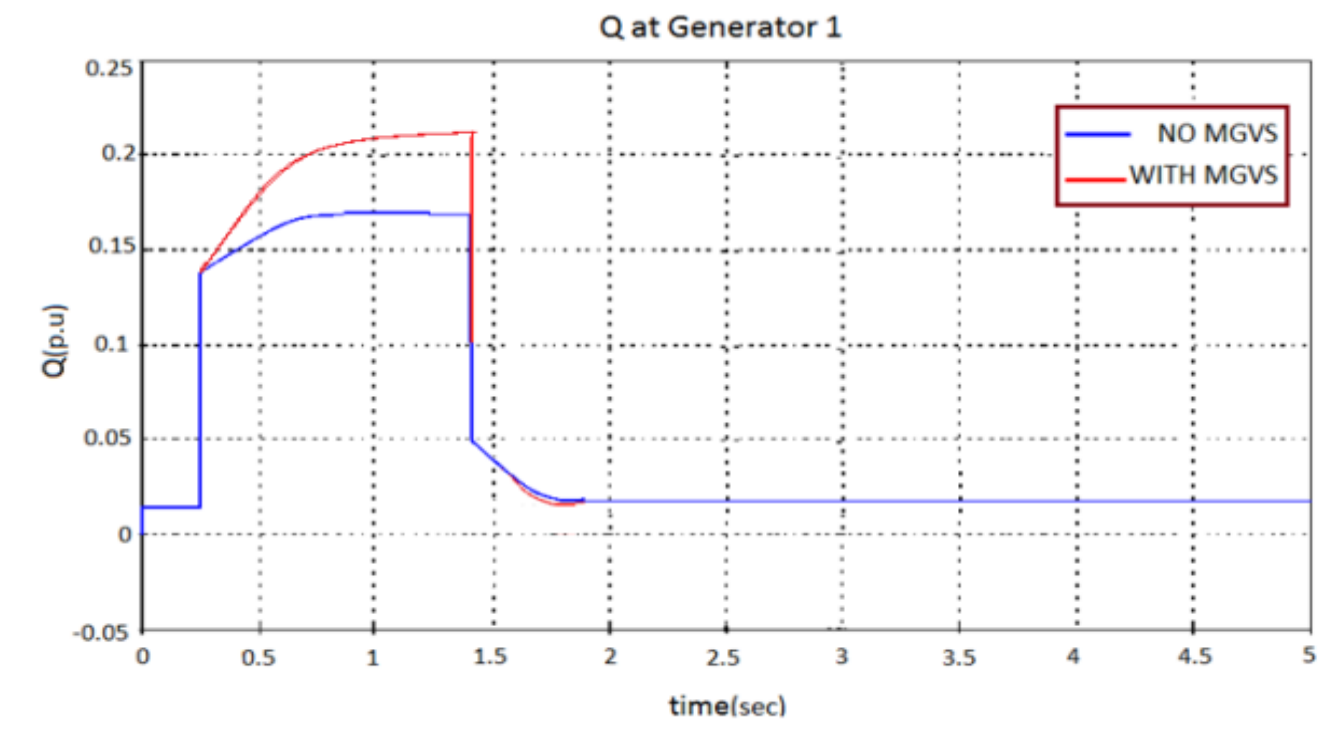

Fig. 12: Comparison of Reactive Power Generation Related to Resource (1), with MGVS and without It 


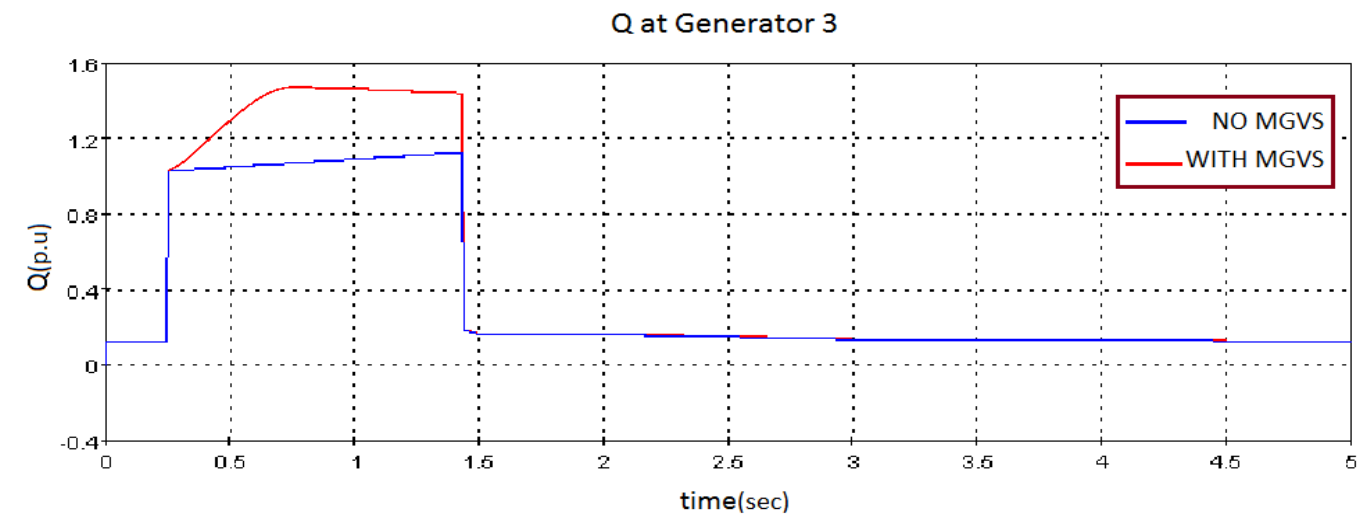

Fig.13: Comparison of Reactive Power Generation Related to Resource (3), with MGVS and without It

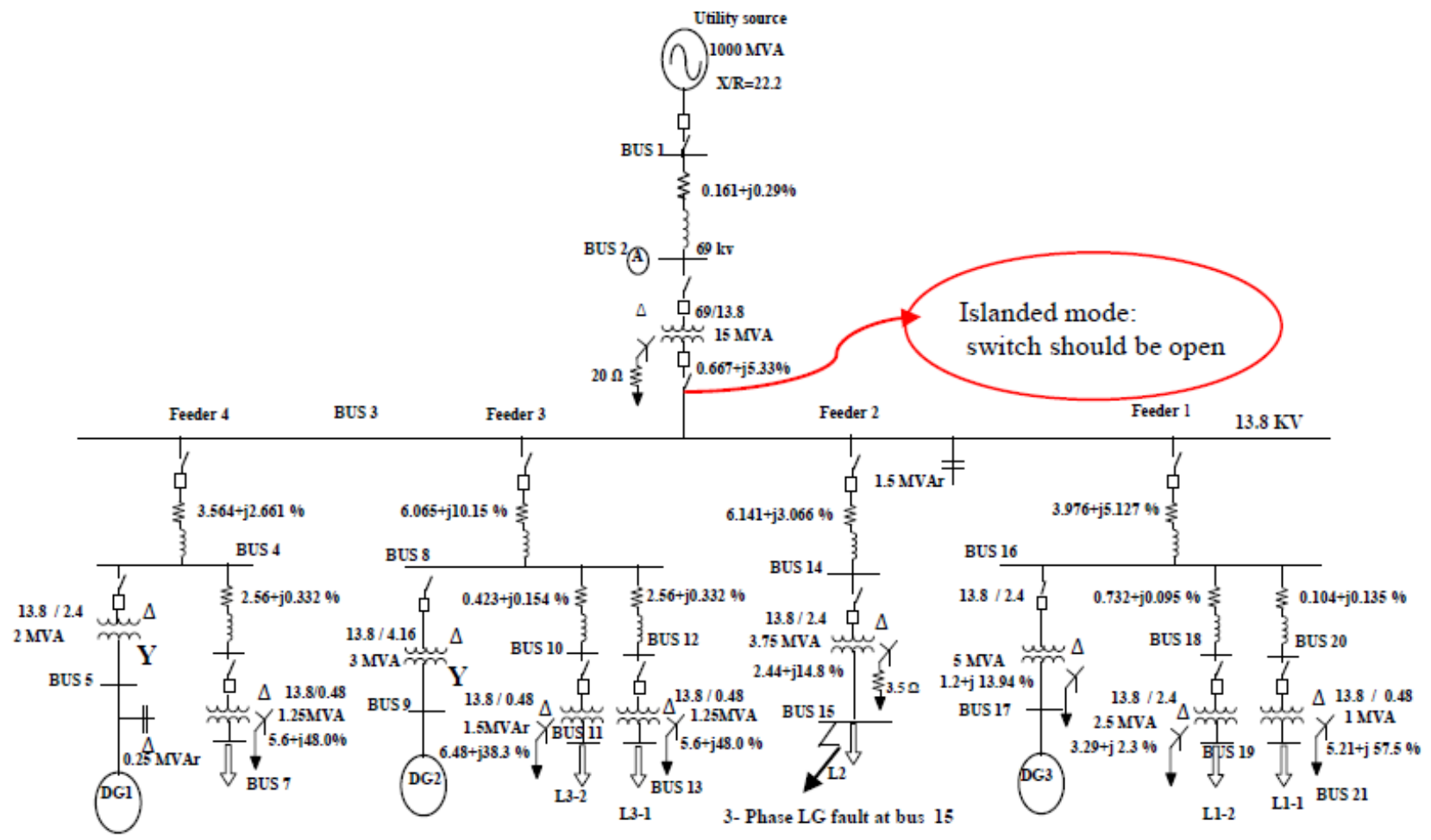

Fig. 14: Test System- IEEE 21-Bus Microgrid in Islanded Mode

\section{Conclusion}

Disturbances that occur in microgrids cause variations in buses voltage. These variations are sometimes very intensive so that they could likely result in the collapse of microgrid if the fault lasts more.

Hence, a voltage stabilizer is used that improves voltage profiles of the microgrid buses in this investigation. This stabilizer is formed by a set of control blocks and its output is a voltage signal that would be divided between the DGs in the microgrid. Indeed, output signal of MGVS is effective to coordinate the DGs reactive power generation and supply the lost generation.

Therefore, since the generated reactive power of resources depends on voltage, each resource generates an amount of reactive power causing to improve the dynamic voltage of the load buses in the microgrid.

The validation of this stabilizer performance was confirmed for microgrids containing synchronous machine based DGs, in another research. So that, in this paper, it is applied to a microgrid containing photovoltaic resources that are known as power electronic interfaced type of DGs. Hence, regarding obtained results of this paper and the results of prior research, it can be concluded that utilizing this "MicroGrid Voltage Stabilizer" with proper control parameters, improves dynamic voltage profile of buses in any microgrid (containing power electronic converter based DG or synchronous generator based DG or combination of them). In other words, this microgrid stabilizer is a control based and low cost stabilizer, that can be used in any type of microgrid. 


\section{Appendix}

Table 4: Specifications of Each Photovoltaic Cell and the Derived Module

\begin{tabular}{|c|c|c|c|c|c|}
\hline \multicolumn{3}{|c|}{ Module } & \multicolumn{3}{c|}{ Photovoltaic cell } \\
\hline $\mathbf{V}_{\mathbf{p v}}$ & $\mathbf{P}_{\mathbf{p v}}$ & $\mathbf{V}_{\text {o.c }}$ & $\mathbf{I}_{\text {s.c }}$ & Voltage at $\mathbf{P}_{\max }$ & $\mathbf{P}$ \\
\hline 103.2 & 510.8 & 22.2 & 5.45 & 17.2 & 85.14 \\
\hline
\end{tabular}

\section{References}

[1] Robert Lasseter, Abbas Akhil, Chris Marnay et al. Integration of distributed energy resources- The CERTS microGrid concept. U.S. Department of Energy, White Paper LBNL-50829, April 2002.

[2] B. A. Robbinsy, A. D. Domínguez-Garcíay, C N. Hadjicostisz. Control of distributed energy resources for reactive power support. North American Power Sy mposium (NAPS) Conference, Aug. 2011.

[3] P. Kundur. Power system stability and control. McGraw-Hill, Inc.1994.

[4] J. A. Peças Lopes, C. L. Moreira, A. G. Madureira. Defining control strategies for analysing microGrids islanded operation. IEEE Transactions on Power Systems, v21, May, 2006.

[5] Ritwik Majumder, Arindam Ghosh, Gerard Ledwich et al. Enhancing the stability of an autonomous microgrid using DSTATCOM. International Journal of Emerging Electric Power Systems, v10, Dec., 2009.

[6] N. L. Soultanis, S. A. Papathanasiou, N.D. Hatziargyriou. A stability algorithm for the dynamic analysis of inverter dominated unbalanced LV mic rogrids. IEEE Transactions on Power Systems, v22, Feb., 2007, pp. 294-304.

[7] M. S. Zabihi., E. Soleimani, S. Farhangi. Photovoltaic manufacturing, system design and application trend in Iran. Renewable Energy Journal of Elsevier Science, v15, n1, September 1998.

[8] The MathWorks Inc. (2009) MATLAB Help. Help Document.

[9] Athimulam Kalirasu, Subharensu Sekar Dash. Simulation of closed loop controlled boost converter for solar instalation. Serbian Journal of Electrical Engineering, v7, n 1, May 2010, pp.121130.

[10] Z. Ye, R. Walling, L. Garces et al. Study and development of anti-islanding control for gridconnected inverters. General Electric Global Research Center Niskayuna, New York, May 2004,pp. 21.
[11] J. A. Peças Lopes, C. L. Moreira, A. G. Madureira et al. Control strategies for microgrids emergency operation. International Conference on Future Power Systems, Nov. 2005.

[12] Rashad M. Kamel, Aymen Chaouachi, Ken Nagasaka. Detailed analys is of microgrid stability during islanding mode under different load conditions. Engineering journals of SCIRP, May 2011.

[13] A. Engler. Control of parallel operating battery inverters. International Conference on Hybrid Power System, 2000, pp. 1-4

[14] Hannu Laaksonen, Pekka Saari, Risto Komulainen. Voltage and frequency control of inverter based weak LV network microgrid. International Conference on Future Power Systems, Nov. 2005, pp. 1-6.

[15] P. L. Jeffrey. Modeling of Dynamic Loads for Voltage Stability Studies. M.S Thesis in Tennessee Technological University, 2007.

\section{Authors'Profile}

Maedeh Mahzarnia (1985-), Iran. She received the B.Sc. from Noshirvani University of Babol, Iran in 2009. Currently she is a student of M.Sc. in Noshirvani University of Babol. Her research directions include smart grids, microgrids and voltage stability in these systems.

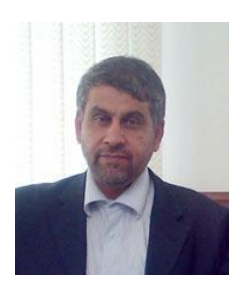

Abdolreza Sheikholeslami (1956 -), Iran. He received the B.Sc. from Mazandaran University, Iran in 1979 and M.Sc. and $\mathrm{PhD}$ in Strathclyde University U.K in 1989.

Currently, He is Associated Professor of Noshirvani University, Babol, Iran. His research directions include power electronic, power quality and smart grid.

How to cite this paper: Maedeh Mahzarnia, Abdolreza Sheikholeslami,"Improvement the Dynamic Voltage Profile by a Voltage Stabilizer in Microgrids with a Type of Inverter Based Resource", IJISA, vol.5, no.9, pp.39-46, 2013. DOI: 10.5815/ijisa.2013.09.05 